TITLE:

\title{
The effect of gastric inhibitory polypeptide on intestinal glucose absorption and intestinal motility in mice.
}

\section{AUTHOR(S):}

Ogawa, Eiichi; Hosokawa, Masaya; Harada, Norio; Yamane, Shunsuke; Hamasaki, Akihiro; Toyoda, Kentaro; Fujimoto, Shimpei; ... Yamada, Yuichiro; Seino, Yutaka; Inagaki, Nobuya

\section{CITATION:}

Ogawa, Eiichi ... [et al]. The effect of gastric inhibitory polypeptide on intestinal glucose absorption and intestinal motility in mice.. Biochemical and biophysical research communications 2011, 404(1): 115-120

\section{ISSUE DATE:}

2011-01-07

URL:

http://hdl.handle.net/2433/134608

\section{RIGHT:}

(C) 2010 Elsevier Inc.; This is not the published version. Please cite only the published version.; この論文は出版社版でありません。引用の際に は出版社版をご確認ご利用ください。 
The effect of gastric inhibitory polypeptide on intestinal glucose absorption and intestinal motility in mice

Eiichi Ogawa ${ }^{1}$, Masaya Hosokawa ${ }^{1,2}$, Norio Harada ${ }^{1}$, Shunsuke Yamane ${ }^{1}$, Akihiro Hamasaki ${ }^{1}$, Kentaro Toyoda ${ }^{1}$, Shimpei Fujimoto ${ }^{1}$, Yoshihito Fujita ${ }^{1}$, Kazuhito Fukuda ${ }^{1}$, Katsushi Tsukiyama $^{1,3}$, Yuichiro Yamada ${ }^{1,3}$, Yutaka Seino ${ }^{1,4}$, Nobuya Inagaki ${ }^{1,5}$

${ }^{1}$ Department of Diabetes and Clinical Nutrition, Graduate School of Medicine, Kyoto University, Japan

${ }^{2}$ Faculty of Human Sciences, Tezukayama Gakuin University, Osaka, Japan

${ }^{3}$ Department of Internal Medicine, Division of Endocrinology, Diabetes and Geriatric Medicine, Akita University School of Medicine, Akita, Japan

${ }^{4}$ Kansai Electric Power Hospital, Osaka, Japan

${ }^{5}$ CREST of Japan Science and Technology Cooperation (JST), Kyoto, Japan 
Address correspondence to Nobuya Inagaki, M.D., D.M.Sci.

Department of Diabetes and Clinical Nutrition, Graduate School of

Medicine, Kyoto University, 54 Shogoin, Kawahara-cho, Sakyo-ku, Kyoto

606-8507, Japan

Telephone number:+81-75-751-3562

FAX number:+81-75-771-6601

E-mail: inagaki@metab.kuhp.kyoto-u.ac.jp

Keywords: GIP, Glucose absorption, Intestine

Abbreviations: GIP, Gastric inhibitory polypeptide; GLP-1, glucagon-like-peptide-1;

somatostatin, SST; SGLT, sodium-glucose co-transporter; CSS, cyclosomatostatin 


\section{Abstract}

Gastric inhibitory polypeptide (GIP) is released from the small intestine upon meal ingestion and increases insulin secretion from pancreatic $\beta$ cells. Although the GIP receptor is known to be expressed in small intestine, the effects of GIP in small intestine are not fully understood. This study was designed to clarify the effect of GIP on intestinal glucose absorption and intestinal motility. Intestinal glucose absorption in vivo was measured by single-pass perfusion method. Incorporation of $\left[{ }^{14} \mathrm{C}\right]$-glucose into everted jejunal rings in vitro was used to evaluate the effect of GIP on sodium-glucose co-transporter (SGLT). Motility of small intestine was measured by intestinal transit after oral administration of a non-absorbed marker. Intraperitoneal administration of GIP inhibited glucose absorption in wild-type mice in a concentration-dependent manner, showing maximum decrease at the dosage of $50 \mathrm{nmol} / \mathrm{kg}$ body weight. In glucagon-like-peptide-1 (GLP-1) receptor-deficient mice, GIP inhibited glucose absorption as in wild-type mice. In vitro examination of $\left[{ }^{14} \mathrm{C}\right]$-glucose uptake revealed that $100 \mathrm{nM}$ GIP did not change SGLT-dependent glucose uptake in wild-type mice. After intraperitoneal administration of GIP (50 nmol/kg body weight), small intestinal transit was inhibited to $40 \%$ in both wild-type and GLP-1 receptor-deficient mice. Furthermore, a somatostatin receptor antagonist, cyclosomatostatin, reduced the 
inhibitory effect of GIP on both intestinal transit and glucose absorption in wild-type mice. These results demonstrate that exogenous GIP inhibits intestinal glucose absorption by reducing intestinal motility through a somatostatin-mediated pathway rather than through a GLP-1-mediated pathway. 


\section{Introduction}

Gastric inhibitory polypeptide (GIP), also called glucose-dependent insulinotropic polypeptide, is an incretin of 42-amino-acid polypeptide synthesized by K-cells of the duodenum and small intestine [1]. We previously generated GIP receptor-deficient mice $\left(\mathrm{GIPR}^{-/-}\right.$mice $)$and showed that $\mathrm{GIPR}^{-/-}$mice have higher blood glucose levels as well as impaired initial insulin response after oral glucose load [2]. Thus, early insulin secretion stimulated by GIP plays an important role in glucose tolerance after oral glucose load.

While GIP receptor mRNA was reported to be present in rat gut [3], the role of the GIP receptor in the gut has not been fully clarified. In the present in vivo study, we investigated the effect of exogenous GIP on intestinal glucose absorption in mice using the intestinal perfusion method. We investigated the effect of exogenous GIP on SGLT-dependent glucose uptake in vitro by using the everted jejunal ring method. Because intestinal motility and absorption are positively related $[4,5]$, we investigated the effect of exogenous GIP on gastrointestinal motility by non-absorbed marker method. Since SST secretion has been reported to be stimulated by GIP and to prolong intestinal motility, we also investigated the involvement of SST in the inhibitory effect of exogenous GIP on both intestinal transit and intestinal glucose absorption by using 
somatostatin receptor antagonist. Our results demonstrate that exogenous GIP inhibits intestinal glucose absorption by reducing intestinal motility through a somatostatin-mediated pathway rather than through a GLP-1-mediated pathway. 


\section{Materials and methods}

Animals

Male C57/BL6J mice weighing 25 to $30 \mathrm{~g}$ (8-14 weeks old) were housed in a temperature $\left(25 \pm 2^{\circ} \mathrm{C}\right)$ - and moisture $(50 \%)$-controlled room with a 12 -h light/dark cycle (6:00 AM/6:00 PM). The mice were fed standard mouse chow (Oriental Yeast, Osaka) and tap water ad libitium, and used as wild-type mice.

Generation of $\mathrm{GIPR}^{-/-}$mice and GLP-1 receptor-deficient mice (GLP-1R ${ }^{-/-}$ mice) was described previously $[2,6]$. GLP- $1 \mathrm{R}^{-/-}$mice were kindly provided by Dr. Daniel J. Drucker [6]. Age-matched male GIPR ${ }^{-/-}$and GLP-1R ${ }^{-/-}$mice were used in the experiments. The Animal Care Committee of Kyoto University Graduate School of Medicine approved animal care and procedures.

\section{Materials}

Synthetic human GIP was purchased from Peptide Institute (Osaka, Japan). The somatostatin receptor antagonist, cyclo(7-aminoheptanoyl-PHE-D-TRP-LYS-THR(BZL)) (cyclosomatostatin (CSS) ) and somatostain 28 (SST) were from Sigma Chemical Co. (St. Louis, MO). All other chemicals were of reagent grade. 
Single-pass perfusion method [7] was used to measure the effect of exogenous GIP or SST on intestinal glucose absorption using C57/BL6J mice. Preperfusion was done for a 45-min equilibration period and the samples were discarded. Three 15-min samples were then collected. GIP or SST was administered intraperitoneally at 60-min after starting the preperfusion according to the protocol (Fig.1A). The change of absorption was calculated as the glucose concentration of the first sample collected (Period 1) minus the glucose concentration of the last sample collected (Period 2), and expressed as per centimeter perfused bowel. Negative values indicate an inhibitory effect on absorption; positive values indicate an increased effect on absorption.

Glucose uptake in jejunum in vitro

Incorporation of D-glucose into everted jejunal rings was determined as described previously [8]. SGLT-dependent glucose uptake for 15-min was determined as the glucose uptake in the absence of phlorizin minus the glucose uptake in the presence of phlorizin.

Small intestinal transit after intraperitoneal administration of GIP

Transit through the stomach and small intestine was measured by administering a non-absorbed marker containing $10 \%$ charcoal suspension in $5 \%$ gum Arabic, as 
previously described [9]. The mice were given $0.2 \mathrm{ml}$ of the suspension by gavage through a straight blunt-ended feeding needle. GIP (50 nmol/kg body weight) or SST (75 $\mathrm{nmol} / \mathrm{kg}$ body weight) or vehicle (saline) was administered intraperitoneally $15-\mathrm{min}$ prior to the administration of the non-absorbed marker. CSS ( $1 \mu \mathrm{g} / \mathrm{kg}$ body weight), or vehicle (saline) was intraperitoneally administered 10-min prior to GIP administration.

Plasma GIP and SST assays

Blood was collected from the tail vein before the intraperitoneal administration of GIP (50 nmol/kg body weight) and collected again 20-min after the administration. ELISA assay kit was used according to the manufacture's instruction for the determination of plasma total GIP concentration (Linco Research, St. Charles, MO) and SST concentration (Phoenix Pharmaceuticals INC., Belmont, CA), respectively.

Analysis

The results are given as mean \pm standard error (S.E.M., $n=$ number of mice).

Statistical significance was determined using paired and unpaired Student's $t$-test and analysis of variance (ANOVA). $P<0.05$ was considered significant. 


\section{Results}

Perfusion experiment

Inhibition of glucose absorption was calculated by change in glucose concentration in effluent perfusate in wild-type mice (Fig. 1A). Spontaneous inhibition of glucose absorption of $49 \pm 44 \mathrm{nmol} / \mathrm{cm} / 15 \mathrm{~min}$ is shown in saline-administered controls (Fig. 1B). Inhibition of glucose absorption was enhanced to $67 \pm 40,163 \pm 84$, and $409 \pm 96 \mathrm{nmol} / \mathrm{cm} / 15 \mathrm{~min}$ when the amount of intraperitoneally-administered GIP was increased to $12.5,25$, and $50 \mathrm{nmol} / \mathrm{kg}$ body weight, respectively.

Glucose uptake by jejunum in vitro

We investigated glucose uptake by the jejunum in vitro using everted jejunal rings. In the presence of $100 \mathrm{nM}$ GIP in the incubation medium, glucose uptake into jejunal rings in wild-type mice was similar to that in the presence of vehicle (control: $4.2 \pm 0.9 \mu \mathrm{mol} / \mathrm{g}$ weight; GIP: $3.5 \pm 0.9, P=\mathrm{NS}$; Fig. 2A). Additionally, glucose uptake into jejunal rings in $\mathrm{GIPR}^{-/-}$mice was similar to that in wild-type mice (wild-type mice: $4.0 \pm 0.5 \mu \mathrm{mol} / \mathrm{g}$ weight; $\mathrm{GIPR}^{-/-}$mice $4.6 \pm 0.7, P=\mathrm{NS}$; Fig. $\left.2 \mathrm{~B}\right)$. 
Intestinal transit rate was measured by the length of small intestine traversed by the charcoal suspension. In wild-type mice, the intestinal transit rate in GIP-administered mice was significantly less than that in saline-administered control (45 $\pm 8 \%$ vs. $68 \pm 4 \%, P<0.01$; Fig. $3 \mathrm{~A})$. On the other hand, in GIPR ${ }^{-/-}$mice, the intestinal transit rate was similar to that in saline-administered control and GIP-administered mice ( $65 \pm 3 \%$ vs. $63 \pm 4 \%$; Fig. 3B).

Perfusion and intestinal transit in GLP-1 receptor-deficient mice

To determine whether GIP affects intestinal glucose absorption through GLP-1 signaling, inhibition of glucose absorption by GIP was measured in GLP-1R ${ }^{-/}$mice. Inhibition of glucose absorption in GLP-1R ${ }^{-/}$mice was $44 \pm 100 \mathrm{nmol} / \mathrm{cm} / 15 \mathrm{~min}$ in saline-administered control mice and $426 \pm 104 \mathrm{nmol} / \mathrm{cm} / 15 \mathrm{~min}$ in GIP-administered mice $(50 \mathrm{nmol} / \mathrm{kg}$ body weight, $P<0.05$, Fig. 3C). Thus, GIP significantly inhibited glucose absorption in GLP-1 $1 \mathrm{R}^{-/-}$mice.

The intestinal transit rate was also evaluated in GLP-1 $\mathrm{R}^{-/-}$mice, and was $59 \pm$ $13 \%$ in saline-administered control and $42 \pm 7 \%$ in GIP-administered mice, respectively. Thus, GIP significantly inhibited the intestinal transit rate in GLP- $1 \mathrm{R}^{-/-}$mice $(P<0.01$, 
Fig. 3D). Consequently, the genetic disruption of GLP-1 receptor did not affect GIP action on intestinal glucose absorption and intestinal transit.

Involvement of SST in the action of GIP

To determine whether the inhibitory effect of GIP on intestinal transit is due to release of SST, a somatostatin receptor antagonist, CSS $(1 \mu \mathrm{g} / \mathrm{kg}$ body weight), was intraperitoneally administered 10-min prior to GIP administration in wild-type mice (Fig.4A). In the presence of CSS, the intestinal transit rate in GIP-administered wild-type mice was significantly higher than that in the absence of CSS (60 $\pm 3 \%$ vs. 45 $\pm 8 \% ; P<0.01)$. Accordingly, CSS reduced the inhibitory effect of GIP on intestinal transit. Moreover, intraperitoneally-administered SST itself significantly inhibited the intestinal transit rate in wild-type mice compared to control (SST: $37 \pm 5 \%$ vs. control: $68 \pm 4 \%, P<0.01)$

In a perfusion experiment, to confirm that the inhibitory effect of GIP on intestinal glucose absorption is attributable to release of SST, CSS $(1 \mu \mathrm{g} / \mathrm{kg}$ body weight) was intraperitoneally administered 10 -min prior to GIP administration in wild-type mice (Fig.4B). In the presence of CSS, the inhibition of glucose absorption in GIP-administered wild-type mice was significantly lower than that in the absence of 
CSS $(410 \pm 96 \mathrm{nmol} / \mathrm{cm} / 15 \mathrm{~min}$ vs. $-290 \pm 99 \mathrm{nmol} / \mathrm{cm} / 15 \mathrm{~min} ; P<0.01)$. Accordingly,

CSS reduced the inhibitory effect of GIP on intestinal glucose absorption. Furthermore, inhibition of glucose absorption in wild-type mice mice was $49 \pm 44 \mathrm{nmol} / \mathrm{cm} / 15 \mathrm{~min}$ in saline-administered control mice and $278 \pm 63 \mathrm{nmol} / \mathrm{cm} / 15 \mathrm{~min}$ in SST-administered mice $(75 \mathrm{nmol} / \mathrm{kg}$ body weight, $P<0.05)$.

In an experiment of glucose uptake in everted jejunal ring, $100 \mathrm{nM} \mathrm{SST} \mathrm{did} \mathrm{not}$ alter glucose uptake compared to control (control: $4.2 \pm 0.9 \mu \mathrm{mol} / \mathrm{g}$ weight; SST: $4.2 \pm$ $0.4, \mathrm{n}=8 ; P=\mathrm{NS})$.

Measurement of plasma GIP and SST levels

The plasma levels of total GIP and SST in mice were significantly enhanced 20-min after the intraperitoneal GIP-administration at a dosage of $50 \mathrm{nmol} / \mathrm{kg}$ body weight compared to the respective basal levels (GIP: $58 \pm 5 \mathrm{pg} / \mathrm{ml}$ vs. $3400 \pm 257 \mathrm{pg} / \mathrm{ml}$, $\mathrm{n}=8 ; P<0.01 ;$ SST: $9.9 \pm 0.5 \mathrm{ng} / \mathrm{ml}$ vs. $11.9 \pm 0.3 \mathrm{ng} / \mathrm{ml}, \mathrm{n}=8 ; P<0.05)$. 


\section{Discussion}

We investigated the inhibitory effect of exogenous GIP on glucose absorption in small intestine. GIP has been known as an important insulinotropic hormone released from duodenal K cells. However, there have been few reports on the effects of GIP on intestinal glucose absorption. In the present study, GIP was found to inhibit glucose absorption in a concentration-dependent manner by the perfusion method.

Glucose absorption includes two steps in enterocytes, permeation through brush-border membrane and subsequently through basolateral membrane. Glucose and galactose cross the brush-border membrane by means of SGLT-1, which is a rate-limiting step of glucose absorption [10]. Recent in vitro study by Singh et al. found that exogenous GIP stimulates SGLT-dependent glucose aborption by using an Ussing chamber experiment [11]. In the experiment, intestine was fixed between two chambers, and short-circuit-current representing SGLT activity was measured. However, in our experiments using everted jejunal rings, which is another method to measure SGLT-dependent glucose absorption in vitro, the lack of effect of exogenous GIP on SGLT-dependent glucose uptake was shown, and genetic disruption of the GIP receptor was found not to affect SGLT-dependent glucose absorption. The reason why our results and theirs are different is unknown, but may be attributable to difference in method. 
It is generally accepted that there is a positive relationship between intestinal motility and absorption $[4,5]$. It has been shown that increased intestinal motility, besides enhancing the functional surface area, facilitates diffusion of glucose to the transporters of the brush-border membrane by alterring the unstirred water layer [12, 13]. We investigated the effect of GIP on motility of small intestine by evaluating intestinal transit. In the present study, GIP was found to inhibit intestinal transit compared to control in wild-type but not in GIPR ${ }^{-/}$mice. Thus, the inhibitory effect of GIP on glucose absorption may be attributable, in part, to inhibition of intestinal motility.

GLP-1, another incretin hormone, is secreted from L cells found predominantly in ileal mucosa, and is known to be part of the "ileal brake" that acts as an inhibitor of upper gastrointestinal motility [14]. In the present study, GIP was found to inhibit intestinal transit in GLP-1 $\mathrm{R}^{-/-}$mice as well as in wild-type mice, indicating that the inhibitory action of GIP on gastrointestinal transit is not mediated by GLP-1. Furthermore, glucose absorption was found to be inhibited significantly by GIP in GLP-1R ${ }^{-/-}$mice as well as in wild-type mice, suggesting that the primary mechanism of the inhibition of intestinal glucose absorption by GIP most likely does not involve the GLP-1-mediated pathway. 
Recently, Miki et al. reported that GLP-1 inhibited gut motility while GIP did not [15]. In the present study, however, GIP was found to inhibit intestinal transit. The inconsistency could be due to their use of a non-absorbed marker containing a high concentration (as much as 50\%) of glucose to evaluate gut motility, whereas we used a non-absorbed marker without glucose. Intraduodenal infusion of hyperosmolar solution was reported to increase duodenal motility, which is mediated by activation of osmoreceptors in duodenum [16]. In our preliminary experiment on small intestinal transit using $10 \%$ charcoal suspension in 5\% gum Arabic with 50\% glucose, the intestinal transit rate was significantly greater than that when using glucose-free solution ( $88 \pm 8 \%$ v.s. $68 \pm 4 \%, P<0.05$, unpublished data). Therefore, intestinal transit might be enhanced by the high concentration of glucose itself in the suspension, which could conceal a GIP-evoked inhibitory effect on intestinal transit. However, limitations of this study must be considered. While GIP was found to inhibit intestinal transit under the conditions of the present study, the effect of GIP on intestinal transit may differ among the constituents of the food or nutrient. Further investigations are required.

Regarding the GIP dosage applied in the in vivo experiments, low GIP dosage has been used when applied by the route of continuous intravenous administration; GIP $(0.25 \mathrm{nmol} / \mathrm{kg}$ body weight $)$ was reported to stimulate insulin secretion by intravenous 
administration in rat [17] and (GIP $4 \mathrm{pmol} / \mathrm{kg}$ body weight $/ \mathrm{min}$ ) in human [18]. However, high GIP dosage has been used when applied by the other routes of administration than intravenous administration. Indeed, one group has reported that subcutaneous pre-administration of $100 \mu \mathrm{g}$ GIP (approximately $800 \mathrm{nmol} / \mathrm{kg}$ body weight) lowered glucose excursion in oral glucose tolerance test in mice [15] and another group has reported that intraperitoneal administration of [D-Ala ${ }^{2}$ GIP (48 $\mathrm{nmol} / \mathrm{kg}$ body weight/day), a DPP4-resistant analogue, lowered glucose excursion in intraperitoneal glucose tolerance test in mice [19]. In the present study, we applied GIP intraperitoneally at a dosage of $50 \mathrm{nmol} / \mathrm{kg}$ body weight to demonstrate the pharmacological effects of GIP on intestinal transit and glucose absorption, which dosage is comparable to those used in the latter reports.

Regarding the mechanism of inhibition of intestinal transit by GIP, SST secretion has been reported to be stimulated by GIP [20-22] and to prolong intestinal transit $[23,24]$. The SST receptor has five isoforms (sst1-5) and all five receptors have been shown to be expressed in gastrointestinal tract, with high levels of sst 2 receptor in intestine [25]. The sst2 receptors in intestine have been shown not to be expressed on enterocytes or muscle cells, but on myenteric and submucosal plexuses and on neuroendocrine cells in epithelium [26] and also on interstitial cells of Cajal in deep 
muscular plexus [27]. Thus, the mechanisms by which exogenous GIP inhibits intestinal motility through two SST-mediated pathways may be as follows. In the first, exogenous GIP binds to the GIP receptors on the cell surface membrane in SST-containing enteric neurons and/or in mucosal endocrine cells of D cells in gastrointestinal tract and/or in pancreatic islets, resulting in the release of SST. Subsequently, the released SST acts as a neurotransmitter and binds to sst 2 receptors expressed on other neurons in myenteric plexus, parts of which nerve fibers are distributed to muscular cells, permitting inhibition of intestinal motility. In this pathway, the local SST concentration in interneural synaptic space may be increased prominently. In an alternate pathway, SST secreted from D cells flows into systemic circulation through submucosal vessels to reach the neurons in myenteric plexus. Indeed, in the present study, intraperitoneally-administered GIP induced a small but significant increase in plasma SST levels, suggesting involvement of the latter pathway.

In our experiment of intestinal perfusion, GIP was found to inhibit intestinal glucose absorption primarily by reducing intestinal motility. On the other hand, the tissue of everted intestinal ring is set inside-out and distended far from the physiological condition, and thus incapable of reflecting general intestinal motility. Thus, the lack of 
GIP action on glucose uptake in the tissues of everted intestinal ring in the present study may be expected.

Several studies have found that the inhibitory effect of SST on intestinal glucose absorption may be attributable to either the effect of SST on the splanchnic hemodynamics [28] or a direct effect of SST on enterocytes [29]. However, consistent with the present study, another study has found that SST delays intestinal glucose absorption by its inhibitory effect on intestinal motility [24]. SST exerts its inhibitory effect on intestinal glucose absorption by several mechanisms; our results indicate that the inhibitory effect of SST is mediated, at least in part, by alteration of intestinal motility.

In the present study, the somatostatin receptor antagonist CSS was found to reduce the inhibitory effect of GIP on intestinal transit, suggesting that GIP stimulates SST release. In addition, we show that SST itself inhibits intestinal transit and glucose absorption in perfused intestine. Consistently, a recent study has reported that SST inhibits intestinal glucose absorption [29]. Considered together with previous reports, we conclude that exogenous GIP inhibits intestinal transit and glucose absorption indirectly through a somatostatin-mediated pathway. 
One of the physiological roles of GIP is known to be facilitation of nutrient uptake into adipose tissue and bone. In the present study, exogenous GIP was found to inhibit intestinal glucose absorption by reducing intestinal motility. Since this observation was obtained by the action of a supraphysiological level of plasma GIP, it is unclear whether or not the action is associated with already known physiological actions of GIP. In the point of delay of intestinal carbohydrate absorption, however, the biological action of GIP found in the present study appears to be similar to that of medical medicine $\alpha$-glucosidase inhibitor, which does not influence the regulation of energy accumulation in adipose tissue or bone. 


\section{Acknowledgments}

This study was supported by Scientific Research Grants and a Grant for

Leading Project for Biosimulation from the Ministry of Education, Culture, Sports,

Science, and Technology of Japan, a grant from CREST of Japan Science and

Technology Cooperation, and a grant from the Ministry of Health, Labor, and Welfare,

Japan, and also by Kyoto University Global COE Program "Center for Frontier

Medicine". The authors are grateful to Dr. Daniel J. Drucker for kindly providing

GLP-1R $\mathrm{R}^{-/-}$mice. 


\section{References}

[1] Y. Seino, M. Fukushima, D. Yabe, GIP and GLP-1, the two incretin hormones:

Similarities and differences, J. Diab. Invest. 1 (2010) 8-23.

[2] K. Miyawaki, Y. Yamada, H. Yano H, et al., Glucose intolerance caused by a defect in the entero-insular axis : a study in gastric inhibitory polypeptide receptor knockout mice, Proc. Natl. Acad. Sci. USA 96 (1999) 14843-14847.

[3] T.B. Usdin, E. Mezey, D.C. Button, et al., Gastric inhibitory polypeptide receptor, a member of the secretin-vasoactive intestinal peptide receptor family, is widely distributed in peripheral organs and the brain, Endocrinology 133 (1993) 2861-2870.

[4] M Sababi, U.H. Bengtsson, Enhanced intestinal motility influences absorption in anaesthetized rat, Acta. Physiol. Scand. 172 (2001) 115-122.

[5] A.J. Smout, Small intestinal motility, Curr Opin Gastroenterol. 20 (2004) 77-81.

[6] L.A. Scrocchi, T.J. Brown, N. MaClusky, et al., Glucose intolerance but normal satiety in mice with a null mutation in the glucagon-like peptide 1 receptor gene,. Nat. Med. 2 (1996) 1254-1258.

[7] R. Athman, A. Tsocas, O. Presset, et al., In vivo absorption of water and electrolytes in mouse intestin, Application to villin ${ }^{-/}$mice, Am. J. Physiol. Gastrointest. Liver. Physiol. 282 (2002) G634-639. 
[8] K. Tsukiyama, Y. Yamada, K. Miyawaki, et al., Gastric inhibitory polypeptide is the major insulinotropic factor in K(ATP) null mice, Eur. J. Endocrinol. 151 (2004) 407-412.

[9] K. Yamada, M. Hosokawa, S. Fujimoto, et al., The spontaneously diabetic Torii rat with gastroenteropathy, Diabetes Res. Clin. Pract. 75 (2007) 127-134.

[10] M.A. Hediger, M.J. Coady, T.S. Ikeda, et al., Expression cloning and cDNA sequencing of the $\mathrm{Na}^{+}$/glucose co-transpoter, Nature 330 (1987) 379-381.

[11] S.K. Singh, A.C. Bartoo, S. Krishnan, et al., Glucose-dependent insulinotropic polypeptide (GIP) stimulates transepithelial glucose transport, Obesity 16 (2008) $2412-2416$.

[12] F.A. Wilson, J.M. Dietschy., The intestinal unstirred layer: its surface area and effect on active transport kinetics, Biochim. Biophys. Acta. 363 (1974) 112-126.

[13] D.V. Rayner, The relationships between glucose absorption and insulin secretion and the migrating myoelectric complex in the pig, Exp. Physiol. 76 (1991) 67-76.

[14] A. Wettergren, B. Schjoldager, P.E. Mortensen, et al., Truncated GLP-1 (proglucagon 78-107-amido) inhibits gastric and pancreatic functions in man, Dig. Dis. Sci. 38 (1993) 665-673. 
[15] T. Miki, K. Minami, H. Shinozaki, et al., Distinct effects of glucose-dependent insulinotropic polypeptide and glucagon-like peptide-1 on insulin secretion and gut motility, Diabetes 54 (2005) 1956-1963.

[16] H.C. Lin, J.D. Elashoff, G.M. Kwok, et al., Stimulation of duodenal motility by hyperosmolar mannitol depends on local osmoreceptor control, Am. J. Physiol. 266 (1994) G940-943.

[17] E.L. Mazzaferri, L. Ciofalo, L.A. Waters, et al., Effects of gastric inhibitory polypeptide on leucine- and arginine-stimulated insulin release. Am. J. Physiol. 245 (1983) E114-120.

[18] T. Vilsbøll, T. Krarup, S. Madsbad, et al., Defective amplification of the late phase insulin response to glucose by GIP in obese Type II diabetic patients, Diabetologia. 45 (2002) 1111-1119.

[19] B.J. Lamont, D.J. Drucker, Differential antidiabetic efficacy of incretin agonists versus DPP-4 inhibition in high fat fed mice, Diabetes. 57 (2008) 190-198.

[20] J. Szecówka, V. Grill, E. Sandberg, et al., Effect of GIP on the secretion of insulin and somatostatin and the accumulation of cyclic AMP in vitro in the rat, Acta. Endocrinol. (Copenh) 99 (1982) 416-421. 
[21] L. Hansen, J.J. Holst, The effects of duodenal peptides on glucagon-like peptide-1 secretion from the ileum. A duodeno--ileal loop?, Regul. Pept. 110 (2002) 39-45.

[22] J.J. Holst, S.L. Jensen, S. Knuhtsen, et al., Effect of vagus, gastric inhibitory polypeptide, and $\mathrm{HCl}$ on gastrin and somatostatin release from perfused pig antrum, Am. J. Physiol. 244 (1983) G515-522.

[23] G.J. Krejs, Effect of somatostatin and absorption and atropine infusion on intestinal transit tine and fructose absorption in the perfused human jejunum, Diabetes 33 (1984) 548-551.

[24] C. Johansson, O. Wisén, S. Efendić, et al., Effects of somatostatin on gastrointestinal propagation and absorption of oral glucose in man, Digestion 22 (1981) 126-37.

[25] K. Krempels, B. Hunyady, A.M. O'Carroll, et al., Distribution of somatostatin receptor messenger RNAs in the rat gastrointestinal tract, Gastroenterology 112 (1997) 1948-1960.

[26] M. Gugger, B. Waser, A. Kappeler, et al., Cellular detection of sst2A receptors in human gastrointestinal tissue, Gut 53 (2004) 1431-1436. 
[27] C. Sternini, H. Wong, S.V. Wu, et al., Somatostatin 2A receptor is expressed by enteric neurons, and by interstitial cells of Cajal and enterochromaffin-like cells of the gastrointestinal tract, J Comp Neurol. 386 (1997) 396-408.

[28] J. Wahren, Influence of somatostatin on carbohydrate disposal and absorption in diabetes mellitus, Lancet 2 (1976)1213-1216.

[29] F. Féry, L. Tappy, P. Schneiter, et al., Effect of somatostatin on duodenal glucose absorption in man, J. Clin. Endocrinol. Metab. 90 (2005) 4163-4169. 


\section{Figure legends}

Fig. 1 (A) Diagram showing the sampling protocol of intestinal perfusion. The flow rate of the perfusion fluid was $2 \mathrm{ml} / 15 \mathrm{~min}$. Perfusion began with an equilibration period of 45-min, which samples were discarded. The samples of Period 1 and Period 2 were then collected. GIP was administered intraperitoneally 60-min after the beginning of preperfusion. The change of absorption was calculated as the glucose concentration of the first samples collected (Period 1) minus the glucose concentration of the last samples collected (Period 2), and expressed as per centimeter perfused bowel. (B) Concentration-dependence of inhibition of glucose absorption by GIP in wild-type mice. Data are shown as means with S.E.M. (n=6 for each group, $P<0.05$ by ANOVA).

Fig. 2 Glucose uptake in the jejunum. (A) Glucose uptake in the jejunum in wild-type mice in the absence and in the presence of $100 \mathrm{nM}$ GIP. (B) Glucose uptake in the jejunum in wild-type and $\mathrm{GIPR}^{-/-}$mice. SGLT-dependent glucose uptake was determined as the glucose uptake in the absence of $1 \mathrm{mM}$ phlorizin minus the glucose uptake in the presence of $1 \mathrm{mM}$ phlorizin. Data are shown as means with S.E.M. $(\mathrm{n}=8$ for each group). 
Fig. 3 Intestinal transit after oral administration of non-absorbed marker (10\% charcoal suspension in 5\% gum Arabic) in wild-type (A) and GIPR ${ }^{-/-}$(B) mice. Twenty minutes after administration of non-absorbed marker by gavage, the animals were killed and the entire gastrointestinal transit tract was removed. GIP (50 nmol/kg body weight $)$ or saline was administered intraperitoneally 15 -min prior to the administration of non-absorbed marker. Data are shown as means with S.E.M. ( $n=6$ for each group). Statistical significance was determined using students' t test. $* * P<0.01$ compared with control. (C) Inhibition of glucose absorption in GLP- $1 \mathrm{R}^{-/-}$mice with or without intraperitoneal GIP administration as indicated in the legends of Fig 1. (D) Intestinal transit after oral administration of non-absorbed marker in $\mathrm{GLP}^{-1 \mathrm{R}^{-/}}$mice with or without intraperitoneal GIP administration as indicated in the legends of Fig 3A. Data are shown as means with S.E.M. ( $\mathrm{n}=6$ for each group). Statistical significance was determined using students' t test. $* P<0.05$ compared with control.

Fig. 4 (A) Intestinal transit after oral administration of non-absorbed marker in wild-type mice with or without pretreatment of CSS. The rate of transit was determined as indicated in the legend of Fig 3A. GIP or SST or saline was administered intraperitoneally 15-min prior to the administration of non-absorbed marker. CSS or 
saline was intraperitoneally administered 10 -min prior to GIP administration. Data are shown as means with S.E.M. ( $\mathrm{n}=6$ for each group). Statistical significance was determined using students' $\mathrm{t}$ test. $* * P<0.01$ compared with control. $* * * P<0.01$ compared with GIP alone administered mice. (B) Inhibition of glucose absorption by GIP in wild-type mice with or without pretreatment of CSS, and inhibition of glucose absorption by SST. CSS or saline was intraperitoneally administered 10-min prior to GIP administration. Data are shown as means with S.E.M. ( $\mathrm{n}=6$ for each group). Statistical significance was determined using students' t test. $* P<0.05$ compared with control. $* * * P<0.01$ compared with GIP alone administered mice. 
A
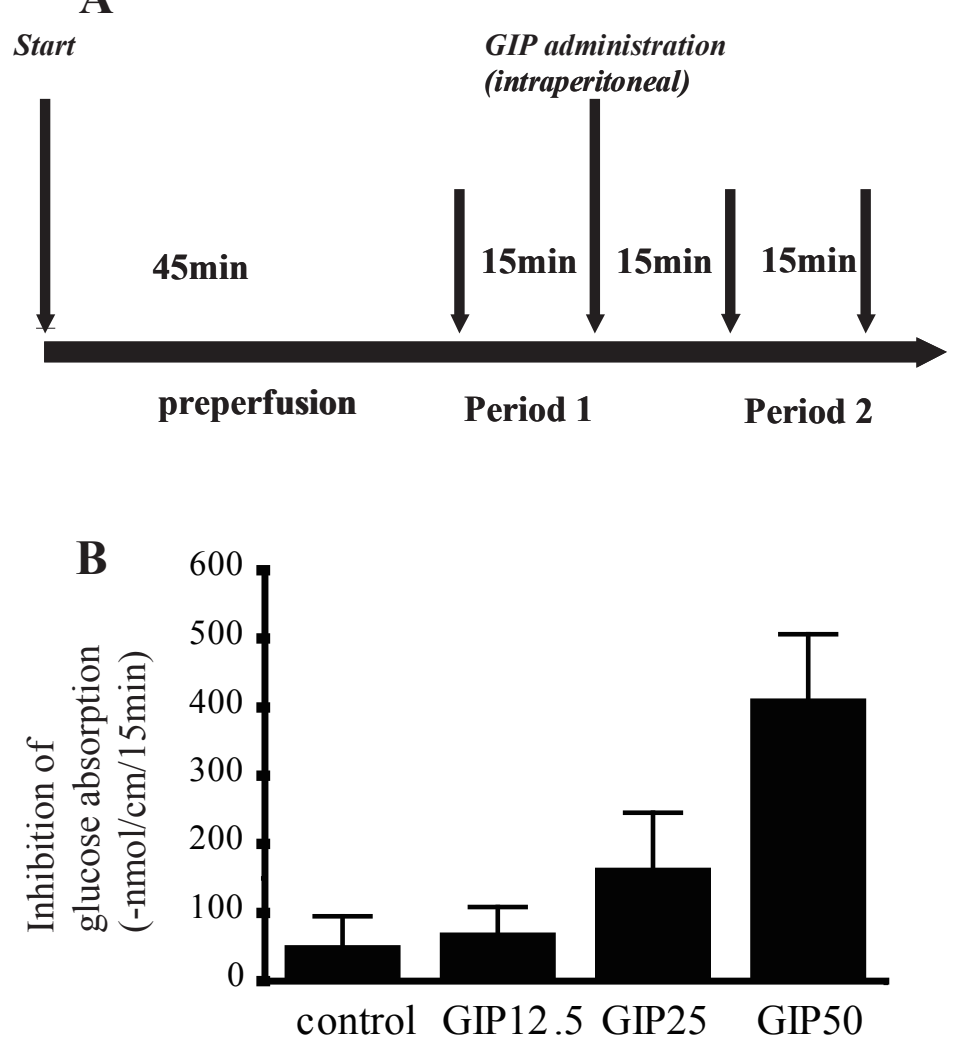

FIG. 1

(nmol/kg) 

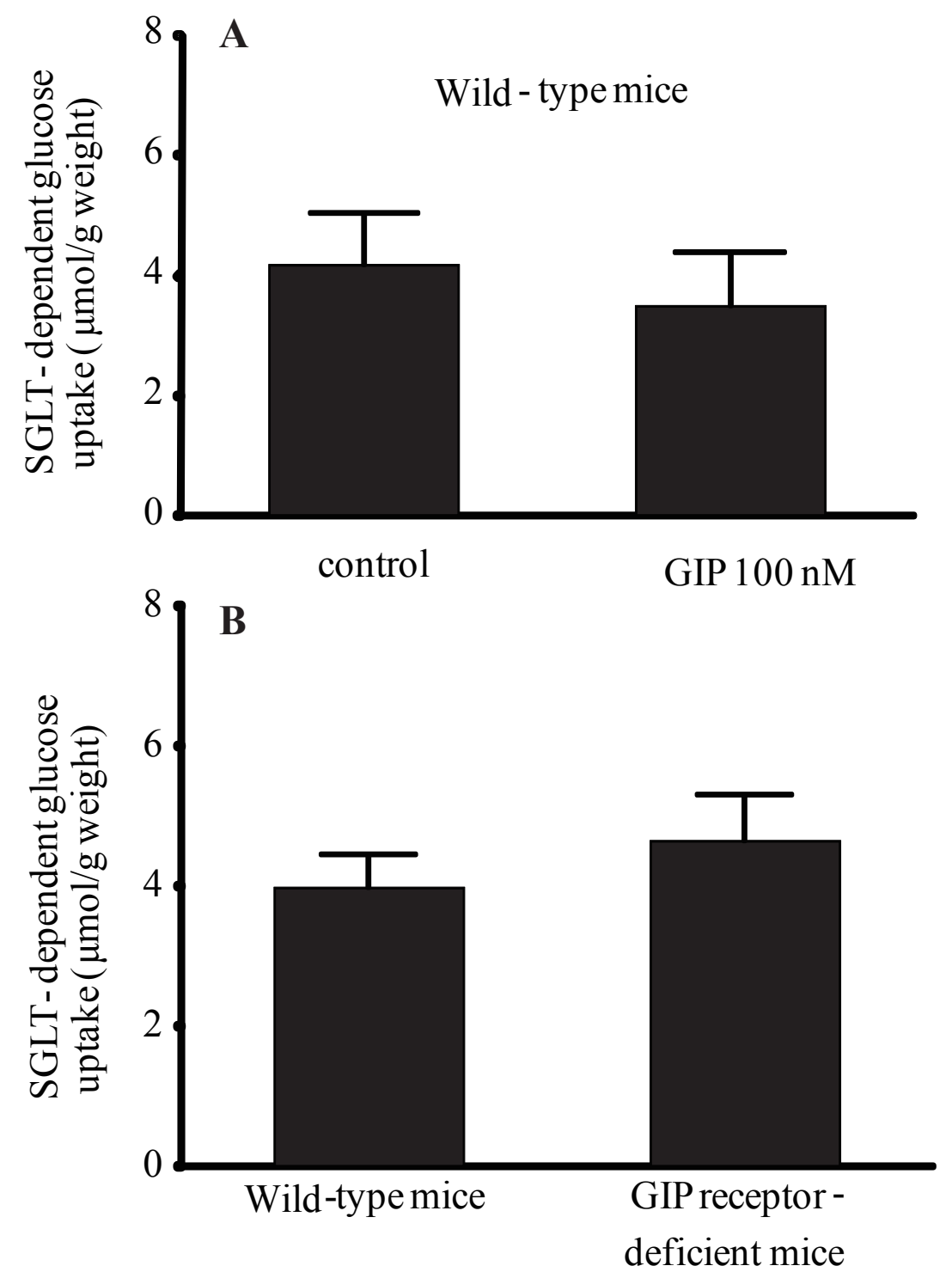

FIG. 2 

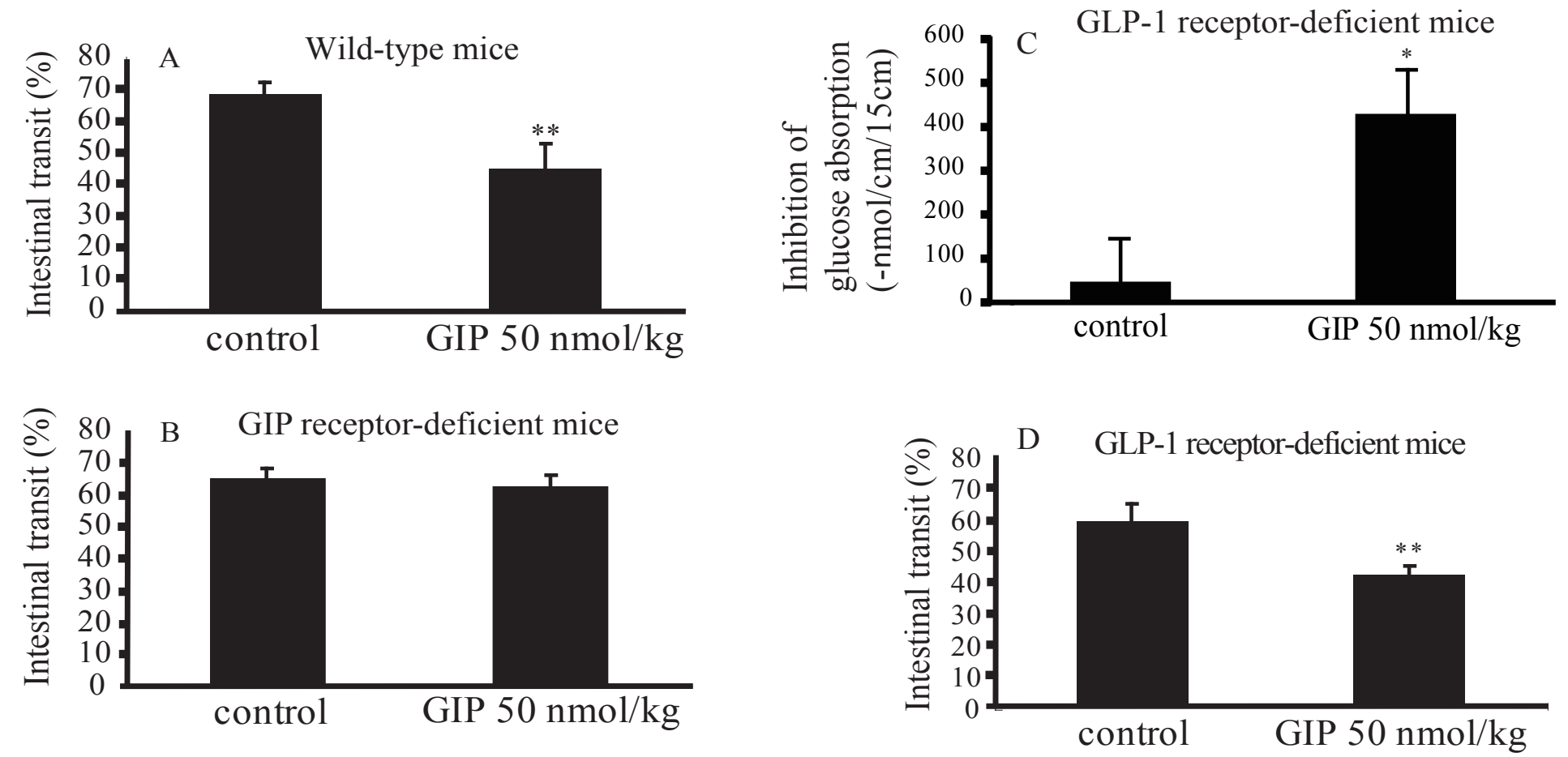

FIG. 3. 

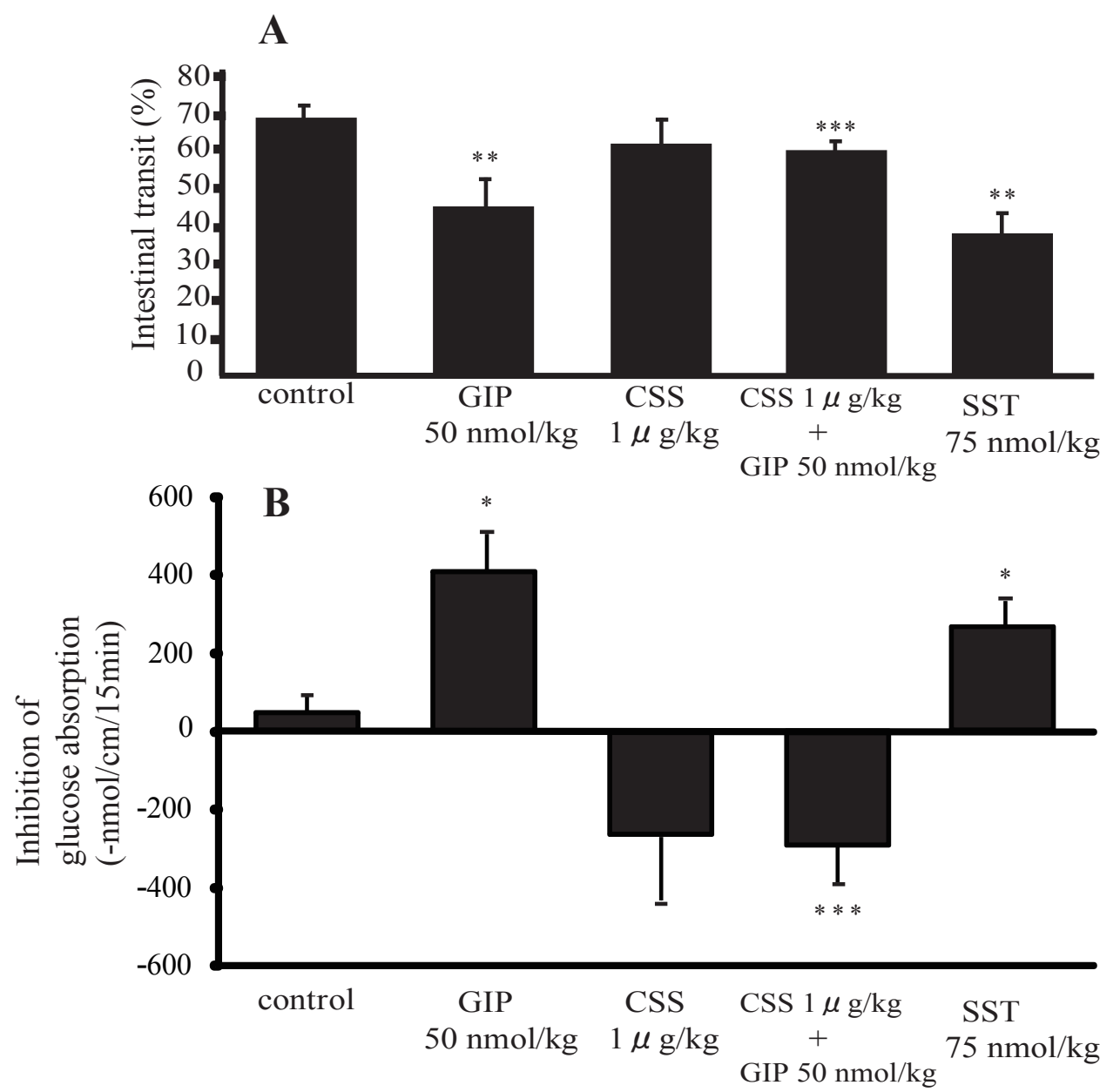

FIG. 4 